\title{
Challenges of Ethical Clearance in International Health Policy and Social Sciences Research: Experiences and Recommendations from a Multi-Country Research Programme
}

\author{
Nancy Edwards, RN, PhD, FCAHS, ${ }^{1}$ \\ Sarah Viehbeck, $\mathrm{PhD}{ }^{2}$ \\ Riitta-Maija Hämäläinen, $\mathrm{MSc}, \mathrm{MPH}, \mathrm{PhD},{ }^{3}$ \\ Diana Rus, BA, MA, PhD (c) ${ }^{4}$ \\ Thomas Skovgaard, $\mathrm{PhD},{ }^{5}$ \\ Ien van de Goor, $\mathrm{PhD},{ }^{6}$ \\ Adriana Valente, MSc, MSSc, ${ }^{7}$ \\ Ahmed Syed, BDS, MSc, ${ }^{8}$ \\ Arja R Aro, PhD, $\mathrm{DSc}^{9}$
}

\begin{abstract}
Background: Research ethics review practices vary considerably across countries and this variability poses a challenge for international research programmes. Although published guidelines exist, which describe underlying principles that should be considered and pragmatic approaches that could be followed in seeking ethics approval, most have roots in biomedical and clinical research. The result is that there is generally less clarity around institutional and/or country-level structures for ethics review of health policy and social sciences research. This is an important
\end{abstract}

\footnotetext{
${ }^{1}$ School of Nursing and Department of Epidemiology and Community Medicine, University of Ottawa, Canada.

${ }^{2}$ University of Ottawa, Canada.

${ }^{3}$ National Institute for Health and Welfare, Finland.

${ }^{4}$ Center for Health Policy and Public Health, Babes-Bolyai University, Cluj-Napoca, Romania.

${ }^{5}$ Institute of Sports Science and Clinical Biomechanics, University of Southern Denmark, Denmark.

${ }^{6}$ Tillburg University, Netherlands.

${ }^{7}$ The National Research Council, Institute of Research on Population and Social Policies, Italy.

${ }^{8}$ NHS Herefordshire, UK.

${ }^{9}$ Unit for Health Promotion Research, University of Southern Denmark, Denmark.
}

Corresponding Author Contact Information: Nancy Edwards at nedwards@uottawa.ca; School of Nursing and Department of Epidemiology and Community Medicine; Room 224 - 1 Stewart St., Ottawa, ON, Canada, K1N 6N5 
gap that needs to be addressed in order to ensure ethical practices in multi-country research programmes.

Context and purpose: This paper explores research ethics requirements for a multicountry health policy research programme and provides recommendations based on experiences in seeking ethics approval. The context for this paper is a five-year, cross-country, European Commission-funded international programme: Research into Policy to enhance Physical Activity (REPOPA).

Results: Ethics requirements and review processes for health policy and social sciences research varied considerably across the seven REPOPA countries. Specifically, requirements and infrastructure for ethics approval have been influenced by how the purpose and domain of health research are defined in legislation, what types of research have been most prominently funded, and international requirements for ethics approval by external funders and journal editors.

Significance: Multi-country research programmes provide an opportunity to enhance and build transparent ethics review practices and to strengthen ethics review structures at all levels. Such programmes also enable reciprocal learning about relevant practices and processes for the ethical conduct of research.

Key Words: Ethics committee; research; health policy; physical activity; multicountry research; research programme

Suggested Citation: Edwards N, Viehbeck S, Hämäläinen R-M, Rus D, Skovgaard T, van de Goor I, Valente A, Syed A, Aro AR. Challenges of ethical clearance in international health policy and social sciences research: experiences and recommendations from a multi-country research programme. Public Health Reviews. 2012;34: epub ahead of print.

\section{INTRODUCTION}

Navigating ethics review requirements and processes is not straightforward, particularly when a mix of sequential projects, each with different leaders from multiple countries, is being undertaken for a funded programme of research. There are some useful published guidelines describing underlying principles that should be considered and pragmatic approaches that could be followed in seeking ethics approval for international research. ${ }^{1,2}$ However, most of these have originated in the domains of biomedical and clinical research. Thus, they do not consider structures for and normative practices of ethics reviews for health policy and social sciences research at either institutional- or country-levels. This is an important gap that needs to be addressed in order to ensure good research ethics practices in these international programmes. The purpose of this paper is to explore research ethics requirements for countries involved in social science and/or health policy research programmes and to provide recommendations for seeking ethics approval in situations where requirements differ among countries. 


\section{International Ethics Review Guidelines}

Expectations of and requirements for ethics reviews are driven in part by international guidelines and agreements, including for example, the regularly updated World Medical Association's Helsinki Declaration. ${ }^{1}$ This internationally accepted standard spells out ethical principles for medical research with human subjects and directs authors to consider relevant "ethical, legal and regulatory norms and standards for research involving human subjects in their own countries as well as applicable international norms and standards". ${ }^{1(p .2)}$ Helsinki Committees or Institutional Review Boards are now required in many countries and may be a requirement for research grant applications or for publishing results in peer-reviewed journals. However, as noted above, the implementation of such approaches is highly variable. Its primary focus has been medical personnel who are engaged in research on the "causes, development and effects of diseases"1(p.1) with the aim of improving "preventive, diagnostic and therapeutic interventions (methods, procedures and treatments)". ${ }^{1(\mathrm{p} .1)}$

The World Health Organization document entitled Operational Guidelines for Ethics Committees that Review Biomedical Research $(2000)^{3}$ includes epidemiological, social, and psychological investigations. Other guidelines exist specifically for epidemiological research, including observational studies. ${ }^{4}$ Such guidance covers issues related not only to physical harm and benefits of research to humans, but also to social dimensions such as privacy concerns and informed consent. The uptake of these guidelines has been reinforced by journal editors, who have agreed through the World Association of Medical Editors, that the documentation of ethics review is a condition for publishing empirical studies. ${ }^{5}$ However, little guidance seems to be available regarding the nature of ethics documentation that is acceptable to journals, particularly for teams conducting multi-jurisdictional research.

An example of public health-specific guidance came from the Nuffield Council on Bioethics in its Public Health: Ethical Issues Report in 2007. 6 This report provides an overall ethical framework for public health interventions and exemplifies the framework through case studies of public health issues.

Among these documents, there is variability in what constitutes research and the extent to which applied health and social sciences research is within scope of ethics review processes. Furthermore, there are inconsistencies in definitions of research subjects (e.g., patients versus organizational decision-makers, policy-makers or leaders) and interventions (e.g., medical, educational, organizational or policy). 


\section{Ethics and EC-Funded Research: The Case of REPOPA}

This paper evolved from the context of a multi-country, European Commission (EC)-funded international programme: Research into Policy to enhance Physical Activity (REPOPA). It aims to integrate research knowledge, expert know-how and real world policy making; promote physical activity in structural policy making; and establish structures and best practices for future health promotion. ${ }^{7}$ It is a five-year programme (October 2011-September 2016) that takes place in six European countries (Denmark, Finland, Italy, the Netherlands, Romania and the United Kingdom), with a Canadian partner responsible for evaluation.

The research programme is in the domain of health policy and social science research. It involves the analysis of policy documents; and primary data collection through surveys, observations and interviews with policy stakeholders. The policies analysed are in the public domain but some of the internal background or government documents, which informed the policies themselves are not, which brings up confidentiality issues. Further, interviews with key stakeholders may reveal opinions and experiences that are socially sensitive or politically-charged and difficult to anonymize. Three interventions will be carried out in several countries. These include game simulation of cross-sectoral stakeholders, guided group-based policy making, and a policy-oriented Delphi process.

In its funding of research, the EC performs an ethics screening on submitted proposals. Standard questions asked of applicants are related to informed consent and privacy; whether the research involves human embryos or fetuses, children, animals, or participants in developing countries; and whether it could have a dual use for military or terrorist purposes. EC-funded research must abide by the Seventh Framework Programme of ethical standards ${ }^{8}$ including the European Charter for Researchers ${ }^{9}$ and the European Charter of Fundamental Rights. ${ }^{10}$ During the grant negotiation period, proposals are screened for ethics issues and those identified are specified in the technical annex, together with procedures that must be followed.

Consistent with the REPOPA contract, the coordinator developed an internal ethics guidance document for the Consortium to counsel how best to secure the rights and interests of partners and subjects involved in the various research settings of REPOPA. This document describes informed consent, the rights of research participants to withdraw from the research; and the needs of informed consent based on disclosure of risks, burden and potential benefits to participants. REPOPA was also asked to provide the EC with a statement indicating whether or not ethics approval was required and to provide certificates of approval or exemption. Therefore, each country team was asked to identify local procedures and requirements for 
ethics review; to determine whether all projects in the programme or only those they were involved with would require review; and to inquire about the need for a staged review since results from some of the early projects would inform full development of the methods for later projects. Leads within each Consortium country consulted with a variety of individuals to understand and clarify local ethics approval processes and the REPOPA Coordinator conferred with the funder to ensure that we met EC requirements. During this process, it became clear that there was tremendous variability in country-specific requirements for ethics approval. These differences are detailed in the following section.

\section{DESCRIPTION OF COUNTRY-SPECIFIC ETHICS REQUIREMENTS}

\section{Denmark}

In 2009, the Danish Ministry of Health initiated a process leading to a new Act on Research Ethics Review of Health Research Projects, which came into force January 1, 2012. ${ }^{11}$ The fundamental aim of this Act is to "secure that health research projects are undertaken such as to be justified with regard to research ethics". ${ }^{11}$ Another core regulating document is the Act on Processing of Personal Data. ${ }^{12}$ Amended in 2011, this Act applies to all (research) projects entailing the processing of data about an identifiable person. However, a project is required to be reported via the Danish Data Protection Agency only when it deals with sensitive matters like racial background or a person's physical or mental condition. Thus, many healthrelated research projects do not have to be reported and systematically monitored by public authorities.

The basic organization of the Danish ethics committee system is a twotiered structure with a national committee and regional sub-committees. Investigations deemed as health research must be approved by the research ethics committee in the region(s) where it is to be conducted. The national committee, among other things, coordinates the regional activities, offers consultative statements on research in developing countries and acts as a board of appeal. The main Danish system does not have institutional review boards; however, some institutions, including universities, have started their own voluntary boards. Denmark has essentially opted not to have formalized ethical review committees on social science research. One reason for this peculiarity seems to be that since this type of research is often important for policy formation, it should "....not be too constrained by ethical demands". ${ }^{13(p .54)}$ 
As REPOPA is centrally managed by a Danish university (University of Southern Denmark, SDU), the coordinator explored the possibility of ethical clearance for the research programme as a whole through SDU. The hope was that such a clearance would have served individual partner countries and their respective ethics clearance processes. However, that was not possible since there is no agency in Denmark to give that kind of clearance and SDU has no institutional review board. The coordinator contacted the National Data Protection Agency and provided a description of the project. The National Data Protection Agency gave a statement that the project did not need to be registered since it contained no sensitive data in their sense of meaning. The coordinator then approached the regional ethics committee. The initial reaction of the regional committee was that REPOPA (not being biomedical) did not fall under its jurisdiction. After a few rounds of exchanges, a formal document was issued indicating that no ethical clearance was needed. This exemption covers all projects within the REPOPA programme of research.

\section{Italy}

In Italy, there are several institutions dealing with issues related to ethics: the Italian Data Protection Authority, the Authority for Communications, and the National Bioethics Committee that was established in 1990. In those cases where special protection is provided by the Personal Data Protection Code of 2003 or an intervention of Italian Data Protection Authority is required, the law mainly refers to particular types of data. Almost no reference is made to "vulnerable populations", whose involvement in other countries may trigger the need for ethics clearance.

The National Bioethics Committee is advisory to the Government, Parliament and other institutions, but does not provide ethics clearance of research projects. Specific bioethics commissions have also been set up with various purposes other than ethics clearance, including for example promotion and protection of human and social values (University L'Orientale, Naples), social responsibility of enterprises (Regional Ethics Committee (CER), Tuscany), supervision of the Codes of Conduct for behaviour inside and outside the University (Universities of L'Aquila, Macerata, Cagliari), and analysis of ethical implications of research projects (National Research Council Research Ethics and Bioethics Advisory Committee).

\footnotetext{
* An occasional reference to vulnerable population is present in the General Authorisation for the Processing of Genetic Data of June 2011, where some cases are listed in which it is appropriate to grant a new authorisation, among which "scientific research involving children and/or other vulnerable individuals that has no direct beneficial impact on them".
} 
Two institutes of the National Research Council are involved in REPOPA. Team members consulted the National Research Council Office for Relations with European Institutions and the Convener of the National Research Council Research Ethics and Bioethics Advisory Committee, and then formulated a voluntary request of ethical clearance of all REPOPA projects from this committee. In their statement of ethics clearance, the committee rendered their "positive opinion" and general authorization of the research as justified by the general competence of their committee members in ethics and bioethics. They recommended that REPOPA follow the principles of research ethics during the course of the research; required that they be informed on the developments and outcomes of the project; and asked that the researchers notify them of any major critical ethical issues arising in the conduct of research.

\section{Finland}

The main Finnish ethical expert bodies in health and social sciences are the National Advisory Board on Research Ethics (TENK), National Advisory Board on Health Care Ethics, and National Committee on Medical Research Ethics (TUKIJA). In 2009, TENK published recommendations for ethical clearance of behavioural, humanistic and social science related research at universities and other research institutes. ${ }^{14}$ The main ethical principles for human sciences are personal autonomy, avoidance of harm and privacy and data protection. The primary role of TUKIJA is to serve as an expert on research ethics and advise regional ethics committees on matters of ethical principles related to medical research. The Finnish Medical Research Act ${ }^{15}$ requires that each district operating a university hospital have at least one ethics committee. The Act includes health care and health sciences research, but leaves out register- or document-based research.

Clinical and medical research is evaluated by the hospital ethical committees. Other research, which involves interactions with people, is evaluated by the Research Ethical Committee of the National Health and Welfare Institute based on rules of procedure in the Institute. Ethical preevaluation has to be requested if research uses samples from human beings or involves bodily integrity; involves children less than 15 years of age; deviates from the information based consent principles; or includes public or published information, register based data and documents, or archives. Researchers may ask for an ethics consultation if research subjects, research funding agencies or partners need an ethics report; if research results will be published in scientific journals; or if a researcher considers ethical consultation necessary. 
Members of the Finnish team are only involved in one REPOPA project and this project involves interviews with policy stakeholders. Thematic research questions, consent forms and an information leaflet for interviewees on REPOPA research were submitted electronically for review, along with a copy of the full REPOPA programme. Ethics approval was obtained. Should the Finnish team members join other REPOPA projects, they will be required to submit these for local ethics review.

\section{The Netherlands}

The Netherlands Organisation for Scientific Research funds most universitybased scientific research while the Netherlands Organisation for Health Research and Development (ZonMw) funds more applied medical, psychological and social behavioural research. Two Acts outline the legal obligations for ethics clearance of health research-The Act on Protection of Personal Information, ${ }^{16}$ and the 1999 Medical Research Involving Human Subjects and/or Embryos Act. ${ }^{17}$ For those research projects, which are considered to be covered by the latter Act, ethics approval is undertaken by an authorized medical ethics review board. Most of these boards are located at academic hospitals/university medical centres and they are registered by the Central Committee on Research Involving Human Subjects. ${ }^{18}$

However, there is no general policy on ethics approval procedures for research in the Netherlands. Therefore, universities differ in their policies and procedures on ethics approval for research that involves persons or personal data. This is why several professional organizations (e.g., psychologists, biomedical scientists) have developed codes-of conduct; and some universities, university faculties and hospitals have set up their own 'ethics review boards' for their local (organization bound) research on topics including human psychology.

For REPOPA projects, the Central Committee on Research Involving Human Subjects was asked whether or not the REPOPA programme required ethics clearance. Since it was deemed not to fall within the range of either of the two Acts governing research, the Committee advised that REPOPA did not need ethical clearance in The Netherlands and provided us with a statement of exemption.

\section{Romania}

The national law regarding the conduct of scientific research in Romania was updated in 2006 and 2011. A National Ethics Code ${ }^{19}$ has also been developed and some of its regulations are now included in the National Education Law. The National Ethics Code includes ethical principles and 
procedures on three main topics: protection of human and animal subjects, environmental safety, and researchers' conduct. With respect to the latter, the Code emphasizes researchers' responsibilities when publishing and disseminating information; and deals with issues like plagiarism, authorship, and improper use of research funds.

After a research grant is awarded, the research team has to start the ethical clearance procedures only if one of the subjects in the law is pertinent to the project. However, all research must respect the national and international settlements that Romania has agreed to, apply general ethical rules and adhere to specific national and international regulations.

Each research university has to have an ethics committee that works under the regulations of the National Ethical Code. Thus, ethics committees are a requirement for all units and institutions that are part of the national system of research and development and involved in developing and implementing programmes of research, disseminating research findings and applying for research funding.

With respect to REPOPA, the legal requirements and the University's Ethical Committee Regulations were consulted to determine if ethics approval was required for each of the projects the Romanian team was involved in. According to the current legislation, there was no need for ethical clearance; since the research does not include clinical tests, the use of biological samples or human embryos; or the use of personal data or vulnerable populations. An ethics approval exemption was issued.

\section{United Kingdom}

In the UK, funding and coordinating particular areas of research, including the arts, humanities, and all areas of science and engineering, is done by Research Councils UK (RCUK). RCUK is a strategic partnership among seven publicly funded research councils from across the full spectrum of health, social science, natural science, technological, and engineering research.

The National Research Ethics Service provides information and guidance to potential applicants for research and development and ethics approval in the UK. In an effort to streamline health and social care/community research applications, the National Research Ethics Service has developed a single online system called "Integrated Research Application System (IRAS)". The IRAS application form uses filters to ensure that the data collected and collated, and consequently the permissions and approvals required, are appropriate to the type of study, capturing the information needed for relevant approvals from nine review bodies. Therefore, only one application needs to be completed. 
The first step in the process was to establish whether the projects of the REPOPA programme in which the UK was participating were considered "research" by the National Research Ethics Service. Based on the overall aims of REPOPA, it was initially not clear if these projects were research or service evaluations. Following discussions with the local research and development office, it was concluded that the project should be classified as research.

The next step in the process was to assess requirements for ethical approval. As the REPOPA project in which the UK was participating included only National Health Services staff and no patients, no ethical clearances were needed. However, the programme was found to require formal research and development approval from the local National Health Services Trust's research and development office as it involved National Health Services' facilities. For this reason, an IRAS application form was completed and submitted along with the necessary documents, which included interview invitation letters, consent forms and interview questions.

\section{Canada}

Research institutions eligible to receive research funds from Canada's three federal funding councils are obliged to follow shared ethics guidelines, the Tri-council Policy Statement on Ethics Involving Humans (1997; 2010). ${ }^{20}$ Universities, teaching hospitals and some other organizations (e.g., School Boards, public health units) have created institutional review boards. The ambit of these boards is locally defined and some will only review certain types of studies (e.g., medical or social sciences research). Reciprocal agreements among boards for the review of projects involving the recruitment of human subjects in more than one organization are variable.

Two main issues arose as we considered the ethics approval process in Canada. The first concerned whether or not ethics approval was required for an evaluation initiative, since the Canadian lead is responsible for the evaluation work package. This is a "grey zone" in the Tri-Council ethics guidelines with quality assurance initiatives, for instance, not necessarily requiring ethics approval. We met with the university ethics protocol officer and described the approach and intent of the evaluation components of REPOPA. The second issue was the need for overall ethics approval of the research programme by the lead institution and the approval, according to local practice for each research project. Initially, we were advised that if ethics approval from the lead institution (University of Southern Denmark) was provided for the overall project, we could then include all REPOPA team members as evaluation participants. However, when it became evident that an ethics exemption would be provided by Denmark, we were advised that all 
REPOPA countries would need to provide documentation of ethics clearance or exemption as per local practice and we would submit the evaluation project for review by our University's health and social sciences ethics review board.

\section{DISCUSSION}

\section{Influences on Review Requirements}

We found considerable variations in ethics review requirements for health policy and social sciences research across the seven countries. These requirements were influenced by how health research was defined in legislation ${ }^{11}$; the type of data collection used (e.g., Denmark excludes research involving document review, interviews and surveys); the field, discipline or domain of research (e.g., Denmark excludes social science); and the purpose of the study (e.g., Canada does not normally require ethics approval for quality assurance projects).

Furthermore, human subjects that were covered by legislation varied. Most ethics documents outlined requirements and procedures to protect "vulnerable" populations but the way this term was defined and the examples of vulnerable populations provided differed substantially. In part, these differences reflected the orientation of ethics guidelines to clinical/ patient populations and/or to a broader array of potential study subjects. In Canada, for instance, applied health and social research is clearly covered by guidelines and there is specific reference to vulnerable populations regardless of study settings (e.g., hospitals, communities, or workplaces). These guidelines also outline specific considerations for different types of vulnerable populations such as children and Aboriginal peoples. ${ }^{20}$

There have been a number of international and historical influences on ethics review practices in European REPOPA countries. A funding condition from external international funding agencies, such as the United States National Institutes of Health, for ethics clearance was described as having been a stimulus for the development of institutional review boards and procedures within some countries. However, the clinical and biomedical focus of this research had reportedly led to a stronger infrastructure for ethics review in these fields, with less attention having been given to developing robust ethics review practices for health policy and social science research. Furthermore, several country partners identified the emerging requirements of journal editors for published studies to include a statement of ethics clearance as a stimulus for setting up structures and boards for ethics review in some institutions. 


\section{Ethics Infrastructure and Processes}

In several countries (Denmark, The Netherlands, Italy and Romania), the national infrastructure for the ethics' review of policy and social sciences research was either fragmented or absent, particularly in comparison with the national infrastructure in place for clinical and biomedical research. This infrastructure gap included a lack of targeted guidelines for ethical clearance and the lack of institutional review boards with experience in these research domains. In three of these settings, the REPOPA programme was deemed to be outside the ambit of existing medical review boards and there were no alternatives proposed for ethics review. In the case of Italy, a voluntary review was undertaken by the board of the National Research Council where REPOPA researchers were based. While team members in each of these four countries consulted with both national and local authorities regarding ethics review, it was apparent that local practices were a factor influencing whether or not a voluntary review by a medical board was deemed to be an option or a reasonable course of action by local authorities even when ethics review was not required.

The fact that some REPOPA countries had ethics committees solely dealing with biomedical investigations was also a constraint since this seemed to suggest that the responsibility and expertise of these committees were in relation to medical research. It was speculated that such committees and their members might not have the relevant competencies to evaluate the benefits, potential harms and risks, and overall research quality of the REPOPA projects. This raises the question of what an exemption from research ethics review means. Our experience suggests that there are different factors at play in determining what warrants an exemption, making this ethics' safeguard challenging to interpret.

\section{Programmatic Research}

For the three countries that provided an ethics exemption (Denmark, The Netherlands and Romania), a description of the overall programme of research, submitted to the EC was reviewed. In Denmark, the REPOPA ethical guidance document prepared by the Coordinator and a more detailed description of the research to be carried out was provided to authorities. The programme of research document lacked some of the specific details required by those countries with an obligatory ethics approval process. For instance, the overall programme of research did not include details of interview questions or participant eligibility criteria and did not include consent forms. During the voluntary approval process undertaken in Italy, one of the team leads was asked to provide some of this more detailed information verbally. 
In the case of Finland and Canada, these types of details had to be provided as part of their ethics submissions. The requirements in the UK were different compared to other countries. They did not need an ethics approval as the projects they participated in only involved staff and no patients. However, an application had to be made for an R\&D approval before the work could be undertaken.

\section{Equivalence in Ethics Review Practice}

REPOPA also faced the general question of recognition of "equivalence" of different bodies providing ethical clearance across national boundaries. ${ }^{21}$ Each body, whatever its name, has specific aims, procedures for selection of members, degree of independence and operating procedures for review. As variations in ethics review practices across jurisdictions have been reported, ${ }^{22}$ it has been recommended that awareness of the expertise and activity of these review bodies should be built. ${ }^{23}$ Our experience in the REPOPA programme suggests that this awareness needs to be strengthened alongside appropriate structures to support ethics review by committees.

\section{RECOMMENDATIONS}

Both pragmatic and structural recommendations follow from our experience. The reader should bear in mind that these arise from a single programme of research involving only seven countries.

\section{Pragmatic Recommendations}

Our pragmatic recommendations for international applied health social science research programs may help guide discussions about review requirements and approval processes and shared principles/guidelines, among team members.

1. Identify and collate ethics requirements across settings. Summarize what type and level of ethics approval is required in each of your settings (e.g., country-level and/or institutional-level). Consider both ethical and legal requirements (such as information privacy). Identify discrepancies in these requirements and review approval processes across settings, so you can plan how to navigate these. Be prepared to explain these differences in requirements when seeking advice on how to proceed with local ethics approvals.

2. Consider a phased approach for obtaining ethics approvals. A phased approach may be needed when your program of research involves a 
series of sequenced projects, ethics review is required in one setting before it can be obtained in another, or there is reciprocity among ethics review boards. Discussions with local authorities will help you develop a plan to organize the optimal sequence of ethics submissions.

3. In the absence of formal ethics requirements, agree to standard nomenclature, procedures and ethics principles. Formal requirements for ethics review should not, in and of themselves, set the bar for good ethical practices. Every research project team should adhere to good ethical practices. Even if the infrastructure and framework for ethics approval for your particular type of projects is not in place, discuss principles that will be used by your team to conduct research in an ethical manner. If ethics guidelines are not in place to guide your research activities, consider using relevant guidelines from other countries or international organizations. ${ }^{1-3}$ Develop an ethics' guidance document for your project but avoid definitional traps. Among REPOPA partners, we found a wide range of definitions in ethics guidelines for terms like "vulnerable populations" and "interventions". In developing a guidance document, consider how research methods may put individuals or communities at risk, and how these risks can be communicated to and mitigated for participants.

\section{Structural Recommendations}

Our structural recommendations are more preliminary and warrant further consultation with other international teams undertaking applied health and social sciences research across a wider range of countries. We offer these recommendations to stimulate discussion within the EC and among national bodies that are influencing normative practices for ethics within their respective jurisdictions and at the institutional level.

1. International health policy and social science research programmes provide an important basis for understanding and strengthening ethics review in these areas. For example, do those institutions that review only individual projects within programmes of research versus the entire programme of research reach different conclusions or provide different guidance on the ethical conduct of health policy and social science studies? Are ethics review committees for medical research able to appropriately consider and review the ethics issues for social sciences research?

2. Reasons for ethical exemptions need to be understood not only in the context of legal and ethical frameworks and common practices, but also in the context of national and local ethics review structures. Examining why exemptions are occurring and what normative expectations they reflect would strengthen the development of ethics frameworks. 
3. An historical perspective may help explain differences in ethics requirements among countries. Thus, an in-depth historical examination of inter-country differences in the ethics review requirements for health policy and social science research would advance our understanding of emergent normative practices.

\section{CONCLUSION}

Using a multi-country health policy and social sciences research programme as an example, this paper highlighted considerable variability in ethics practices. International research endeavors provide an important opportunity to enhance and build transparent ethical practices and to strengthen ethics review structures at all levels. Cross-national projects like REPOPA provide the opportunity for reciprocal learning about relevant practices and processes for the ethical conduct of research. Standardization of nomenclature, procedures and definitions of ethical principles for the full scope of research in health, including policy and social sciences may be one promising mechanism to enable greater consistency in international research.

\section{Acronyms List:}

REPOPA $=$ Research into Policy to enhance Physical Activity

About the Authors: Dr. Nancy Edwards is a Full Professor in the School of Nursing, and the Department of Epidemiology and Community Medicine, University of Ottawa.

Dr. Sarah Viehbeck is a Post-doctoral fellow working with Dr. Edwards, University of Ottawa, Canada.

Dr. Riitta-Maija Hämäläinen is a Senior Researcher at the National Institute for Health and Welfare, Finland.

Diana Rus is a Researcher at the Center for Health Policy and Public Health, BabesBolyai University, Cluj-Napoca, Netherlands.

Dr. Thomas Skovgaard is an Associate Professor and Head of Study of Movment, Sport and Society at the Institute of Sports Science and Clinical Biomechanics, University of Southern Denmark, Denmark.

Dr. Ien van de Goor is a Senior Reseacher and Program Leader, Effectiveness of Individual Prevention and Professor at Tillburg University, The Netherlands.

Dr. Adriana Valente is a Researcher in the field of the formation of awareness, and in the valuation and communication of Science at The National Research Council, Institute of Research on Population and Social Policies, Italy.

Dr. Ahmed Syed is Health Intelligence Officer at NHS Herefordshire. United Kingdom. Dr. Arja R Aro is a Professor and Head of the Unit for Health Promotion Research at the University of Southern Denmark. 
Acknowledgements: The Research into Policy to enhance Physical Activity (REPOPA) project is funded by European Seventh Framework Programme (FP7/ 2007-2013) under grant agreement no 281532. Neither the European Commission nor any other person on its behalf is responsible for any use that may be made of the information contained therein.

The authors gratefully acknowledge all members of the REPOPA Consortium for their work on the programme overall, Mette Winge Fredsgaard, REPOPA Secretary, for her contributions of project documentation used in this manuscript and Katie Hoogeveen for her assistance with referencing and formatting.

Conflicts of Interest: A portion of Dr. van de Goor's research is within a research program conducted as part of her endorsed Chair in Effectiveness of Individual Prevention. The Chair is funded by a Dutch Health Insurance Company.

\section{REFERENCES}

1. World Medical Association. WMA Declaration of Helsinki - ethical principles for medical research involving human subjects. WMA; 2008. Available from URL: http://www.wma.net/en/30publications/10policies/b3/ (Accessed 19 September 2012).

2. National Institutes of Health. Pursuing potential research participants protections: guiding principles for ethical research. NIH; 2012. Available from URL: http://www.nih.gov/health/clinicaltrials/highlights/2012-08-ethicalresearch. htm (Accessed 28 November 2012).

3. World Health Organization. Operational guidelines for ethics committees that review biomedical research. Geneva: WHO; 2000. Available from URL: http:// www.who.int/tdr/publications/documents/ethics.pdf (Accessed 19 September 2012)

4. Council for International Organizations of Medical Sciences. International ethical guidelines for epidemiological studies. Am J Epidemiol. 2009;170: 1451-2.

5. World Association of Medical Editors Publication Ethics Committee. Publication ethics policies for medical journals. WAME; 2012. Available from URL: http://www.wame.org/resources/ethics-resources/publication-ethics-policiesfor-medical-journals/ (Accessed 19 September 2012).

6. Nuffield Council on Bioethics. Public health: ethical issues. London: Nuffield Council on Bioethics; 2007. Available from URL: http://www.nuffield bioethics.org/sites/default/files/Public\%20health\%20-\%20ethical\%20issues. pdf (Accessed 19 September 2012).

7. Research into Policy to Enhance Physical Activity. REPOPA; 2011. Available from URL: www.repopa.eu (Accessed 19 September 2012).

8. European Commission. Getting through ethics review. CORDIS Community Research and Development Information Service. EC; updated 15 June 2011. Available from URL: http://cordis.europa.eu/fp7/ethics_en.html (Accessed 19 September 2012). 
9. European Commission. The European charter for researchers. EC; 2005. Available from URL: http://ec.europa.eu/euraxess/index.cfm/rights/european Charter (Accessed 16 January 2013).

10. European Union. Charter of fundamental rights of the European Union. Official J Eur Communities. 2000;364:1-22.

11. Act on Research ethics Review of Health Research Projects. Denmark. 1 November 2012. Available from URL: http://www.cvk.sum.dk/English/acton abiomedicalresearch.aspx (Accessed 19 September 2012).

12. The Danish Data Protection Agency. Compiled version of the Act on Processing of Personal Data. Denmark. 31 May 2000, updated 10 May 2011. Available from URL: http://www.datatilsynet.dk/english/the-act-on-processing-of-personal -data/read-the-act-on-processing-of-personal-data/compiled-version-of-theact-on-processing-of-personal-data/ (Accessed 19 September 2012).

13. Israel M, Hay I. Research Ethics for Social Scientists. Pine Forge Press; 2006. p.54.

14. National Advisory Board on Research Ethics. Ethical principles of research in the humanities and social and behavioural sciences and proposals for ethical review. Helsinki. 2009.

15. National Committee on Medical Research Ethics. Medical Research Act. Finland. 2010. Available from URL: http://www.finlex.fi/en/laki/kaannokset/ 1999/en19990488.pdf (Accessed 16 January 2013).

16. Personal Data Protection Act. Netherlands. Updated 15 December 2005. Available from URL: http://www.ivir.nl/legislation/nl/personaldataprotection act.html (Accessed 16 January 2013).

17. Regulations on medical research involving human subjects (Medical Research (Human Subjects) Act. The Netherlands. 1 March 2006. Available from URL: http://www.ccmo-online.nl/hipe/uploads/downloads_catw/Medical\%20 Research\%20involving\%20Human\%20Subjects\%20Act\%20March\%2001 \%202006.pdf (Accessed 17 January 2013).

18. Central Committee on Research inv. Human Subjects. CCMO; 2004, updated September 2012. Available from URL: http://www.ccmo-online.nl/main. asp?pid=1\&taal=1 (Accessed 26 September 2012).

19. National Ethics Code. Romania. Official Monitor. 4 June 2004. Available from URL: www.monitoruljuridic.ro/act/lege-nr-206-din-27-mai-2004-privind-buna -conduita-in-cercetarea-stiintifica-dezvoltarea-tehnologica-si-inovare-emitentparlamentul-publicat-52457.html (Accessed 16 January 2013). [In Romanian]

20. Canadian Institutes of Health Research, Natural Sciences and Engineering Research Council of Canada, Social Sciences and Humanities Research Council of Canada. Tri-Council policy statement: ethical conduct for research involving humans. Her Majesty the Queen in Right of Canada; December 2010. Available from URL: http://www.pre.ethics.gc.ca/pdf/eng/tcps2/TCPS _2_FINAL_Web.pdf (Accessed 19 September 2012). 
21. Claudot F, Alla F, Fresson J, Calvez T, Coudane H, Bonaïti-Pellié C. Ethics and observational studies in medical research: various rules in a common framework. Int J Epidemiol. 2009;38:1104-8.

22. Greene SM, Geiger AM. A review finds that multicenter studies face substantial challenges but strategies exist to achieve Institutional Review Board approval. J Clin Epidemiol. 2006;59:784-90.

23. Cuttini M, Saracci R. Commentary: can we facilitate the ethical approval of international observational studies? Int J Epidemiol. 2009;38:1108-9. 